\title{
Psicanálise e Educação: Reflexões Sobre o Caminho para a Ética do Desejo
}

Psicoanálisis y Educación: Reflexiones Sobre el Camino Hacia la Ética del Deseo

Psychoanalysis and Education: Reflections on the Path to the Ethics of Desire

Marina Junqueira Cançado

ORCID: http://orcid.org/0000-0001-5983-995X Universidade Federal de Goiás, Goiás/Brasil

Declaração de Direito Autoral

A submissão de originais para este periódico implica na transferência, pelos autores, dos direitos de publicação impressa e digital. Os direitos autorais para os artigos publicados são do autor, com direitos do periódico sobre a primeira publicação. Os autores somente poderão utilizar os mesmos resultados em outras publicações indicando claramente este periódico como o meio da publicação original. Em virtude de sermos um periódico de acesso aberto, permite-se o uso gratuito dos artigos em aplicações educacionais e científicas desde que citada a fonte conforme a licença CC-BY da Creative Commons.

\section{Resumo}

O presente ensaio faz uma reflexão sobre a função ética da educação, a partir da ótica da psicanálise. Inicialmente, elucida como Freud trabalha o tema da educação em sua obra, desde o início em que nutria esperanças em um possível papel profilático de uma educação baseada na psicanálise, até uma posição mais radical e realista que aponta para a ética por parte dos educadores. Também discute o papel essencial da educação enquanto mecanismo de tentativa de controle pulsional em prol da vida em civilização e como o termo "violência" encontra-se entrelaçado à esse mecanismo, valendo-se das contribuições de outros autores psicanalíticos. Finalmente conclui com a discussão de como pode ser traçado um caminho para uma educação fundada sob a ética do desejo, defendida pela psicanálise. Uma educação que preserve a capacidade do aprendiz de, como sujeito de desejo, deslizar na cadeia significante e existir, sem, contudo, abandonar sua função civilizatória de apresentação da interdição.

Palavras-chaves: Educação; Psicanálise; Violência; Ética.

\section{Resumen}

El presente ensayo hace una reflexión sobre la función ética de la educación, a partir de la óptica del psicoanálisis. En primer lugar, se diluye cómo Freud trabaja el tema de la educación en su obra, desde el principio en que nutría esperanzas en un posible papel profiláctico de una educación basada en el psicoanálisis, hasta una posición más radical y realista que apunta a la ética por parte de los educadores. También discute el papel esencial de la educación como mecanismo de intento de control pulsional en pro de la vida en civilización y como el término "violencia" se encuentra entrelazado con ese mecanismo, valiéndose de las contribuciones de otros autores psicoanalíticos. Finalmente concluye con la discusión de cómo puede ser trazado un camino hacia una educación fundada bajo la ética del deseo, defendida por el psicoanálisis. Una educación que preserve la capacidad del aprendiz de, como sujeto de deseo, deslizar en la cadena significante y existir, sin abandonar su función civilizatoria de presentación de la interdicción.

Palabras clave: Educación; Psicoanálisis; Violencia; Ética. 


\begin{abstract}
The present essay reflects on the ethical function of education, from the point of view of psychoanalysis. Initially, it elucidates how Freud works the theme of education in his work, from the beginning in which he hoped for a possible prophylactic role of an education based on psychoanalysis, to a more radical and realistic position that points to ethics on the part of educators. It also discusses the essential role of education as a mechanism for attempting to control drive for life in civilization and how the term "violence" is intertwined with this mechanism, using the contributions of other psychoanalytic authors. Finally he concludes with the discussion of how a path can be traced to an education founded on the ethic of desire, advocated by psychoanalysis. An education that preserves the apprentice's ability, as a subject of desire, to slip into the signifying chain and to exist, without, however, abandoning its civilizing function of presenting the interdiction.
\end{abstract}

Keywords: Education; Psychoanalysis; Violence; Ethics.

Debruçar-se sobre a temática da educação e o ensino tem sido assunto recorrente na teoria psicanalítica, desde Freud até a atualidade. Em diversos textos ao longo de sua obra, Freud desenvolve ideias e teoriza sobre as funções da educação, tanto numa esfera mais particular da formação do humano quanto na esfera social e seu papel na cultura. Inicialmente, Freud desenvolve sua reflexão sobre a educação com uma visão mais otimista, apontando um possível papel profilático de uma educação que levasse em conta a psicanálise. Contudo, ao final de sua obra, já mais próximo de uma elaboração que abandona o ideal de cura ou possibilidade de fuga da angústia inerente ao humano, aponta para uma postura ética por parte dos educadores no sentido de deixar que o sujeito se constitua como desejante. Nesse sentido, Freud nos leva a uma reflexão sobre o que seria uma educação ética.

Em relação à ciência do ensinar, já de início nos deparamos com o primeiro impasse, algo essencial quando se habita o terreno da Psicanálise. De todos os verbos indicativos do fazer humano, Freud (1925/1996) escolheu três para discorrer sobre o impossível:

Em um primeiro estádio, aceitei o bon mot que estabelece existirem três profissões impossíveis - educar, curar e governar - e eu já estava inteiramente ocupado com a segunda delas. Isso, contudo, não significa que desprezo o alto valor social do trabalho realizado por aqueles de meus amigos que se empenham na educação. (Freud,1925/1996, p.307).

No que nos interessa neste texto, é preciso compreender o que Freud dizia ao incluir o "educar" como operação impossível, mas da qual não podemos nem devemos prescindir em nossa vida em civilização. Sempre considerando as profissões de educar e do psicanalista como ofícios que se entrecruzavam em diversos pontos de um caminho tortuoso, Freud jamais desistiu de elaborar uma escrita sobre como uma e outra dessas profissões se influenciavam.

Quando Oskar Pfister escreveu, em 1913, um livro sobre o Método psicanalítico, que tinha como objetivo introduzir a psicanálise em seu programa de ensino aos educadores e pastores, Freud redige um prefácio apontando os possíveis benefícios da aplicação da psicanálise por parte dos educadores como forma de se prevenir o desenvolvimento da neurose:

As vantagens seriam óbvias. $\mathrm{O}$ educador, por um lado, estaria preparado, por seu conhecimento das disposições humanas gerais da infância, para julgar quais dessas disposições ameaçam conduzir a um desfecho indesejável; e, se a psicanálise pode influenciar o curso 
tomado por tais desenvolvimentos, poderia aplicá-la antes que os sinais de um desenvolvimento desfavorável se estabeleçam. Assim, com o auxílio da análise, ele poderia ter uma influência profilática na criança, enquanto esta ainda é sadia." (Freud, 1913/1996, p.356).

Nesse ponto é possível identificar que, inicialmente, Freud acreditava numa função profilática da educação. Ao longo de sua obra, é possível perceber como suas esperanças numa ação preventiva se esvanecem frente à constatação de que a existência da pulsão de morte levaria a uma constante necessidade de recalque pulsional, advinda exatamente do lugar da educação na cultura, se desejássemos viver em civilização.

Em "O mal-estar na civilização", Freud (1930/1996) aponta três grandes fontes de desprazer contínuo dos humanos. Primeiro, há o nosso desamparo frente a natureza e seus desígnios. Mesmo com os avanços tecnológicos de todas as ciências, ainda não somos capazes de conter ataques e desastres naturais, que sempre nos lembram de nossa inferioridade e finitude. Em segundo lugar, há o sofrimento devido à fragilidade de nossos corpos, que fazem parte dessa mesma natureza. Novamente, apesar de lançarmo-nos exaustivamente à busca de juventude eterna, saúde e força, não se pôde, até o momento, evitar a decrepitude do envelhecimento e da morte. Finalmente, há o sofrimento gerado pelo convívio com os outros humanos. Embora algumas pessoas possam considerar a possiblidade de viverem isoladas da coletividade, a vida sem os outros é ainda mais difícil. Cabe, então, a tentativa de mediação e contenção de impulsos egoístas em prol de uma vida coletiva, atividade altamente desprazerosa e que ocorre com grandes dificuldades e obviamente sem grande sucesso. Sendo assim, a civilização, com suas leis e regras de convivência, visa nada mais do que conter os impulsos destrutivos e narcísicos de cada um de nós em prol de uma convivência "pacífica" entre os humanos.
Coerentemente a essa ideia, a escola teria o papel essencial de apresentar esse preço do convívio coletivo, organizando os conhecimentos, apresentando a cultura com suas regras e limitações da pulsão. O professor assume esse papel de portar inclusive em seu próprio corpo, a representação desse controle pulsional, é o totem simbólico da castração social.

Em sua Conferência XXXIV, na série de Conferências ministradas em 1933, Freud sustenta de forma enfática que a educação deve lidar com a báscula inevitável entre a nãointerferência e a frustração. Isso significa dizer que é preciso buscar um caminho intermediário entre preservar a vida psíquica própria do aluno e sua capacidade individual de interpretar o mundo e, por outro lado, impor ao estudante as leis e regras de convívio social que deverão, necessariamente, frustrar seus impulsos narcísicos e egoístas. Em última instância, nos diz Freud (1933 [1932]): "Vamos tornar claro para nós mesmos qual a tarefa primeira da educação. A criança deve aprender a controlar seus instintos" (p.147). Evidentemente, é através da aprendizagem desse control e, sempre muito limitada e enfrentando inúmeros obstáculos, que o pequeno humano será inserido no contexto social.

É preciso agora discorrer sobre o que é o "humano" para a psicanálise, em especial após a leitura de Jacques Lacan. Isso implica em uma cisão radical da teoria psicanalítica com outras vertentes da ciência. Segundo Terezinha Costa (2008), em sua obra "Psicanálise com crianças", a teorização de Lacan aponta para o fato de que:

O sujeito não nasce pronto como os animais. Ele deve ser constituído, e sua constituição acontece na relação com a fala que passa pela linguagem. E essa fala não significa aprender a articular palavras e formar frases para comunicar-se com os demais, mas significa ir além da necessidade e ter acesso ao desejo. Portanto, se o sujeito é efeito de linguagem, representado de um significante para outro, é 
necessário submeter-se ao significante para que possa falar. (Costa, 2008, p.62).

Tratando o humano como um ser efeito de linguagem, sujeito do inconsciente, é possível compreender a educação como uma operação de alocação da função-sujeito no mundo. Mesmo que o papel inicial dessa inserção na linguagem venha da mãe, dos adultos todos que rodeiam o bebê, por meio da lalíngua ${ }^{1}$ materna, é com a educação que esse humano poderá organizar a linguagem gramaticalmente por meio das mesmas leis de linguagem do Inconsciente: a metáfora e a metonímia.

Isso implica a ideia de que é na família que o bebê receberá da lalíngua de sua línguamãe os significantes puros para que possa futuramente diferenciar-se e deslizar na cadeia de significantes para habitar uma funçãosujeito. É na incorporação de lalíngua que o infans tem a possiblidade de, após assimilá-la, recusar a posição de objeto de gozo da mãe para assumir o lugar de sujeito de desejo. O desejo, visto no outro, no espelho do olhar e linguagem da mãe é o primeiro traço dessa operação. Somente depois será reconhecido e simbolizado, momento em que o bebê poderá ter a possibilidade habitar o mundo simbólico, ou seja, da linguagem que o tornará humano. Assim, quando os significantes primeiros se ligam aos significados da linguagem, quando ele passa também pelo processo educativo, é que poderá se apropriar do saber e do conhecimento de sua cultura, e então habitar como desejante o mundo em que vive.

Ignorando a ideia de Freud em que o papel primordial da educação seria esse de inibir, proibir e suprimir impulsos, algumas escolas pedagógicas penderam unicamente

\footnotetext{
1 Termo apresentado por J. Lacan em seu Seminário, livro 20 "mais, ainda", que designa o que sustenta a linguagem. Uma vez que o próprio inconsciente é constituído como uma linguagem, lalíngua porta os efeitos que são afetos, transmitidos pela lalação da mãe, os primeiros balbucios e serão estofos para toda a estruturação da linguagem e do próprio inconsciente no humano.
}

para um dos lados da báscula, defendendo uma "superliberdade" aos alunos, uma "pedagogia do amor", desarticulada com a função pedagógica da castração. A ideia de autonomia dentro das correntes pedagógicas atuais pesa sobre o estudante, com premissas como a de que, se ensinar é impossível, cabe unicamente ao aluno aprender e que este será agente construtor de seu conhecimento. Essa mudança de posição relega o lugar do professor, do mestre, a um lugar secundário, de puramente apresentar estímulos aos alunos, que construirão sozinhos o saber. Essas escolas passaram a entender o ato educativo como uma espécie de violência contra a criatividade e a individualidade, termos tão utilizados atualmente como bandeira de defesa da construção de um "indivíduo autônomo", como categoria conceitual moderna.

Nesse sentido, Jurandir Freire Costa (1984), em seu livro "Violência e Psicanálise" argumenta contra essa noção de que o ato pedagógico em si possa ser considerado um ato violento. Mesmo que em essência seja coercitivo e frustrante, ensinar é sobretudo, humanizar:

\begin{abstract}
Não pode haver 'violência necessária à humanização do sujeito'. Não pode haver violência no ato de quem leva o outro a respeitar os tabus da cultura e as leis da linguagem. O homem só existe quando internaliza a cultura, através da linguagem e do trabalho. Nesse processo de internalização, inevitavelmente coercitivo, nada pode existir, portanto, de abusivo. (Costa, 1984, p.95).
\end{abstract}

O autor então argumenta que é preciso voltar o olhar à condição básica e necessária ao processo de humanização, que é a dependência 
da criança em relação ao adulto. De fato, essa condição primordial de desamparo é inevitável, uma vez que o pequeno humano necessita do adulto para que suas experiências se tornem significativas. Necessita identificar-se com o adulto para internalizar e tornar seu o que esse lhe apresenta. Deste do estádio especular até a situação de identificação com o professor na escola, é somente via essa apresentação do desejo pelo outro que poderá articular o seu próprio, via mecanismos da linguagem, sempre apresentada por outrem.

Baseado em Freud, ele define o conceito de violência simbólica diferente da violência pura, bruta, pautada em um ato perverso de fazer sofrer ou subjugar o outro. Em suas palavras:

Por esse termo entendemos toda imposição de enunciados sobre o real que leve a criança a adotar como referencial exclusivo de sua orientação no mundo a interpretação fornecida pelo detentor do saber. $\mathrm{O}$ indivíduo cronifica a posição de dependência e perde ou amputa a capacidade de criar seu próprio elenco de significados. $O$ mundo representado sofre uma restrição, fruto da privação sinalética. $\mathrm{O}$ funcionamento mental do sujeito, simbolicamente violentado na infância, torna-se inibido, paralisado ou distorcido, em maior ou menor extensão, conforme a natureza e intensidade da violência." (Costa, 1984, p.75).

Costa (1984) demonstra assim que não é o ato educativo em si que porta a violência, mas a imposição, o cerceamento da função de sujeito-falante do educando que pode se configurar como ato de violência simbólica. $\mathrm{Na}$ realidade, passaremos a compreender essa violência como perversa, já que se comporta como um ato que impede o acesso a simbolização. Assim, é perversa porque interdita a elaboração de linguagem própria, de junção de significantes com significados, nas funções de metáfora e metonímia da linguagem, de elaboração do desejo em signos linguísticos que libertam o sujeito do julgo do Inconsciente puro, Real.

É nesse momento, que cabe ao educador o cuidado que Freud (1913/1996), ainda no prefácio à obra de Pfister, apontou em não impor ao educando, dada sua condição de submissão e dependência, sua própria interpretação do conhecimento. A dependência do aluno deve ser entendida e utilizada no processo educativo na direção da possibilidade de identificação do estudante com o educador, com as ideias e a valorização do ato de conhecer, questionar e investigar o mundo, sem impor uma violência simbólica, que interdita a própria humanização.

Sob determinado aspecto isolado, a responsabilidade de um educador pode talvez exceder a de um médico. Este tem como regra lidar com estruturas psíquicas que já se tornaram rígidas e encontrará na individualidade estabelecida do paciente um limite ao seu próprio êxito, mas, ao mesmo tempo, uma garantia da capacidade do paciente de resistir sozinho. O educador, contudo, trabalha com um material que é plástico e aberto a qualquer impressão, e tem de observar perante si mesmo a obrigação de não moldar a jovem mente de acordo com usas próprias ideias pessoais, mas antes, segundo as disposições e possiblidades do educando (Freud, 1913/1996, p.357).

Mas como evitar ou, de alguma forma, prevenir uma educação assim perversamente violenta? Como pode o educador exercer seu papel de apontar o mundo e o conhecimento aos educandos, independentemente de serem crianças ou adultos, sem impor seu próprio cegamento ante a atitude investigativa da ciência? Em suma, como deixar circular na cadeia significante o sujeito que emerge nesse movimento sem aprisiona-lo em uma teia de significados externos a si e impostos pelo educador? 
Segundo Lajonquière (2017) a crítica de Freud à pedagogia de sua época, e que podemos pensar ainda tão atual nos tempos de hoje, não se deve ao fato de um suposto exagero na quantidade de restrições comportamentais impostas às crianças. Sua crítica persistente, e que atravessa toda a sua obra, aponta para um aspecto central do ideal de educação vigente, que é a transmissão de um conhecimento fechado, pronto e que visa abarcar e justificar toda a realidade. Tal postura pedagógica deixa pouco espaço para o pensamento inovador e criativo e, em última instância para uma sujeição ao desejo, que é a verdadeira ética da psicanálise. Segundo esse autor, educar é transmitir marcas simbólicas que permitam, por parte do educando, conquistar para si um lugar na história, mais ou menos familiar, a partir do qual possa implicar-se com a questão do desejo. Isso aponta para uma postura, por parte do educador, que possibilite a conquista de um lugar de palavra para o aluno, que é a possibilidade real de o sujeito emergir na cadeia significante que o institui.

Colocar o desejo como eixo norteador da educação é colocar o acento correto no que Freud apontou como impossível nessa tarefa. Implica que é preciso considerar sempre a possibilidade de que o aluno não deseje o que lhe apresentam e que, sempre, haverá essa falha entre o que se pretende ensinar e o que o aluno de fato aprende. Esse hiato, essa hiância, é o furo próprio da existência humana e não pode ser suprimido ou elidido por meio de técnicas e metodologias tão buscadas pela pedagogia que busca o sucesso educacional. Em sua época,
Freud apontava que o conhecimento totalitário apresentado pela educação advinha da religião. Hoje, esse totalitarismo advém da ciência, de uma parafernália tecnocientificista que tem resposta para todas as perguntas, alívio para todos os males.

Na verdade, Lacan, em uma entrevista concedida a jornalistas italianos, em 1974, "O triunfo da religião" aponta que a grande maioria dos educadores não reflete sobre o que de fato seja educar. Tomados evidentemente pela angústia de não "conseguirem" atingir a todos e por sempre haver uma boa quantidade de ovelhas que se perdem do rebanho, buscam atenuantes. Esses se multiplicam como representantes de certas visões de homem, e enquanto antes se mostravam ancorados na religião, hoje se refugiam na ciência médica, farmacêutica e psicológica.

Em resumo, o olhar psicanalítico para a educação e suas funções sociais aponta para um ato impossível. Contudo, o impossível Freudiano só reforça a não completude de qualquer solução mágica ou que busque responder de forma simplista o desafio de educar sem cercear e cegar o sujeito quanto ao acesso à linguagem que lhe dará proximidade com o desejo e o mundo do simbólico. Todavia, a reflexão sobre os papeis dos educadores como sendo responsáveis inclusive pela atitude curiosa e especulativa de seus educandos, é a via possível para uma escola, primária, secundária ou superior, que caminhe e seja fundada sob uma ética do desejo, que aponte para a liberdade e para o pensar reflexivo.

\section{Referências}

Costa, J. F. (1984). Violência e Psicanálise. Rio de Janeiro, RJ: Edições Graal.

Costa, T. (2008). Psicanálise com crianças (2a ed.). Rio de Janeiro, RJ: Jorge Zahar.

Freud, S. (1996). Introdução a The PsychoAnalitic Method, de Pfister. In S. Freud. Obras completas $v$. XII. Rio de Janeiro, RJ: Imago. (Obra original publicada em 1913)

Freud, S. (1996). Prefácio à juventude desorientada de Aichhorn. In S. Freud. Obras Completas, v. XIX. Rio de Janeiro,
RJ: Imago, (Obra original publicada em 1925)

Freud, S. (1996). O mal-estar na Civilização. In S. Freud. Obras Completas, v.XXI. Rio de Janeiro, RJ: Imago. (Obra original publicada em 1930)

Freud, S. Conferência XXXIV Explicações, Aplicações e Orientações. (1933 [1932]). In: Freud, S. Obras Completas, v.XXII, Rio de Janeiro, RJ: Imago, 1996. 
Lacan, J. (2005). O Triunfo da Religião, precedido de Discurso aos Católicos. Rio de Janeiro, RJ: Jorge Zahar.
Lajonquière, L. (2017). Sigmund Freud e o Interesse Pedagógico da Psicanálise. In D. Kupermann (org.), Por que Freud hoje? (pp. 243-264). São Paulo, SP: Zagodoni.

\section{Dados sobre a autora:}

- Marina Junqueira Cançado: Mestranda em Psicologia pela UFG (2018-atual). Especialista em Psicologia Jurídica pelo CFP (2012). Especialista em Docência Universitária pela UEG (2007). Graduada em Psicologia pela PUC-Goiás (2004). Atualmente é pesquisadora na área de Psicanálise, arte e literatura, psicanalista clínica e psicóloga no Tribunal Regional do Trabalho $18^{a}$ Região. Tem experiência na área de Psicologia Clínica com o referencial teórico da Psicanálise de Freud e Lacan, psicologia jurídica, qualidade de vida no trabalho, saúde do trabalhador, avaliação psicológica. 